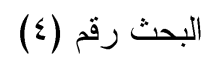

الامج بين طرز الأثاث في تصميمات العمارة الداخلية

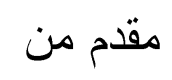

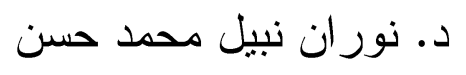

المدرس بقسم الديكور كلية الفنون الجميلة بالقاهرة

$$
\text { (جامعة حلو ان) }
$$




\section{الدمج بين طرز الأثاث في تصميمات العمارة الداخلية}

كلمة طر از نطلق على كل مرحلة فنبة ثابته تستمر لفترة زمنية طويلة و دائماً ما ينطور الطر از بين الجيل و الاخر، و يرجع هذا النطور الى عناصر إقتصادية و

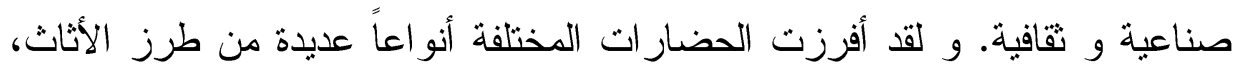
قيوجد العديد من الطرز المختلفة التي تجمع ما بين الإبداع و تحقيق الهدف من

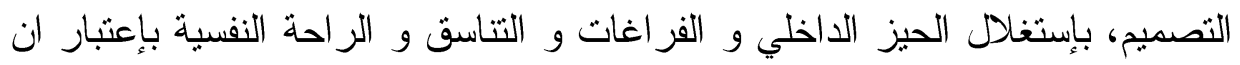
لكل طر از رونقة الخاص به حيث يمكننا دمج أكثر من طر از في نفس التصميم دون الشعور بالتناقض و عدم الملائمة.

\section{ا ـ الطراز الروستيك}

يعد "الروستيك" هو اتجاه في الديكور يعتمد على الأخشاب ، سواء في قطع الأثاث، أو

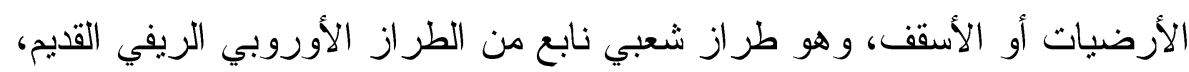

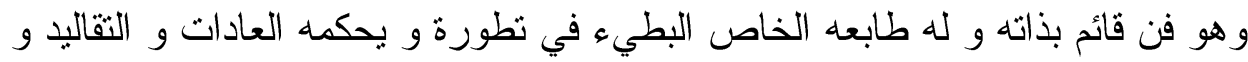

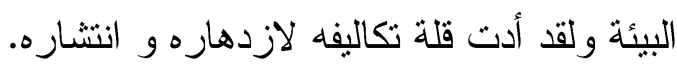
يعتبر طر از الروستيك هو الطر از المفضل لدي محبي الديكور ات العتيقة القائمة على ودهاره

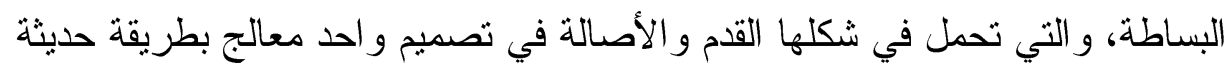

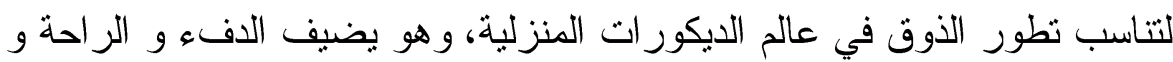

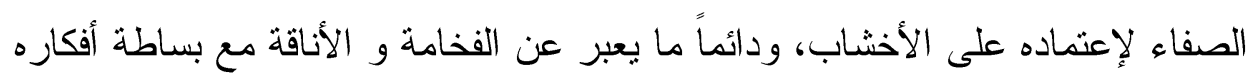
و خاماته الطبيعية.

و من المعروف ان الخشب الطبيعي يمثل جزءاً هاماً من طر از الروستيك في أعمال الديكور الذي بعتمد على استخدام الخامات بطبيعتها ونوظيف ملمسها وطابعها البري هني

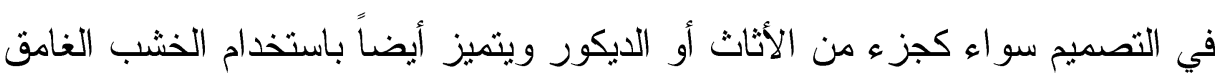
و قطع الاثاث الضخمة.

وككل طرز الديكور وتصميمات العمارة الداخلية هناك سمات مميزة لطر از الروستيك

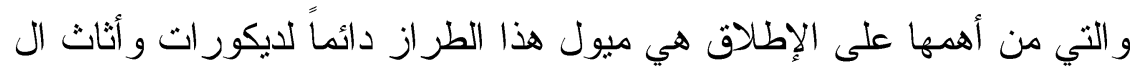


أو بمعنى أخر الديكور ات والأثاث العتيق والتي تثميز بالغنى و الدفء، حيث يحرص مصممو الديكور دائماً على إضفاء اللمسات العتيقة على تصميمات الروسثيك ولثئي و إستخدام الخامات العنيقة ذات الملامس المميزة كالأخشاب و الجلود.

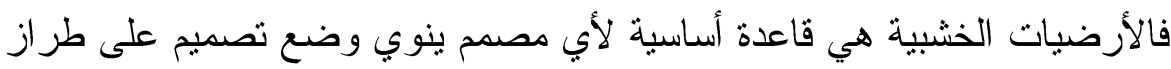
الروستيك، و لا يمنع أبداً في نفس التصميم إستخدام خامات مختلفة ككسوة الأرائك

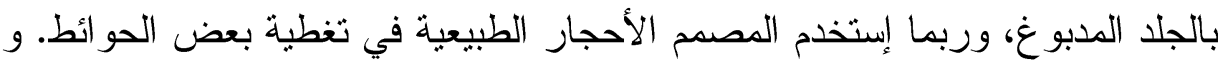
يمكن أحياناً في حالة وجود أسقف خرسانية في المنزل أن يثم كسوتها بالأخشاب ويتم

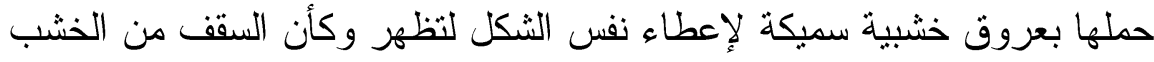
و ويمكن تغطية بعض الحو ائط بالخشب الطبيعي دون دهانه أي على لونه الطبيعي لوني

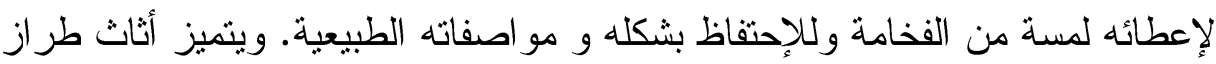
الروستيك بالبساطة في التصميم و القدم في الثكل مع مر اعاة ان يظهر الثكل النهائي بصورة حديثة وهي معادلة صعبة بالطبع لكنها في النهاية تعطينا الفخامة و الأناقة

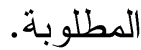

كذلك يتميز طر از منازل الروستيك بتغطية الأرضيات بمفروشات صوفية ذات

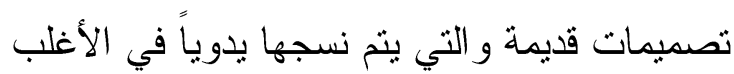

و عند المزج بين طرز الأثاث المختلفة يجب دائماً مراعاة التتاسق بينهما. فلمسات الأخشاب في المنزل دائماً ما نتتاسب مع جميع الأنماط سو اء كان كلاسيكي أو مودرن أو روستيك

\section{صور توضح نماذج مختلفة لمطابخ روستيك}

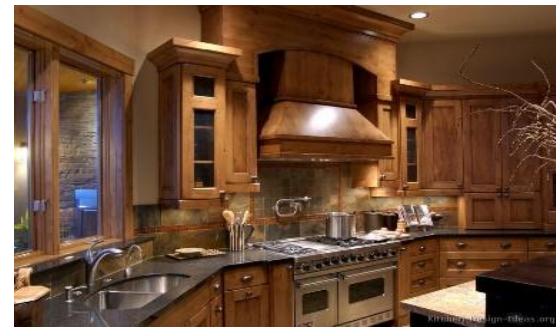

بتميز باستغلال كافة مسطحاته الر أسية في تنفيذ منطبات مستخدمي المطبخ.

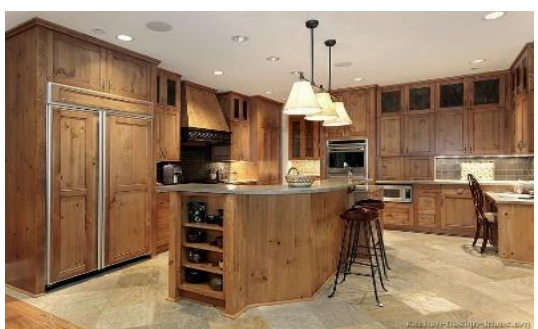

يتميز بقوة البانوهات التي يتسم بها الطراز الروستيك القديم، واستخذام العروق الخشبية في الأسقف، واستغلادل مساحة منتصف المطبخ لوضع الحوض. 


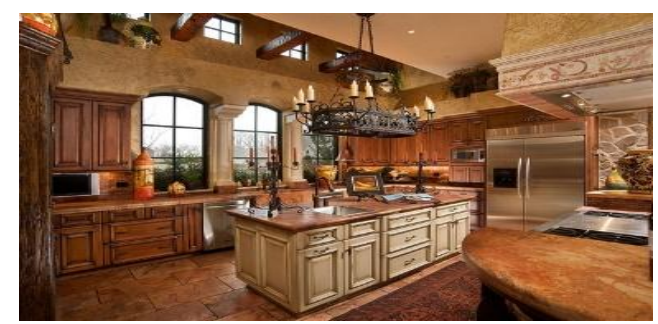

يتميز بمعالجة الطراز الروستيك بطريقة عصرية مي استغلال كافة مساحات المطبخ

\section{نماذج مختلفة لغرف نوم روستيك}

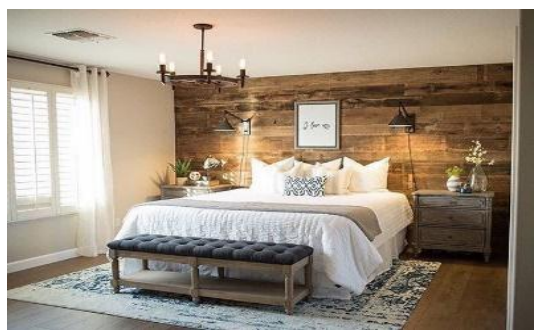

تبسيط الطراز الروستيك في تصميم الغرفة وجعله

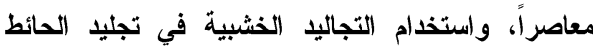
الخلفي للسرير.

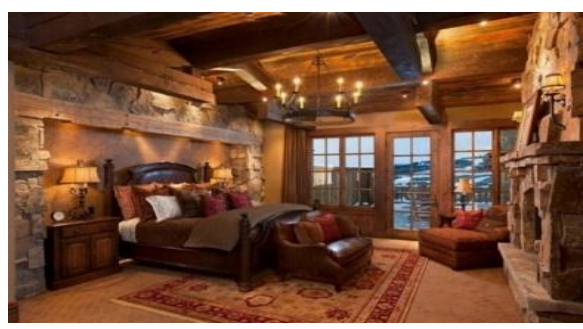

وضوح استخدام الاخشاب بكثرة في كافة أنحاء الغرفة و توظيفها في الأسقف و الأرضيات و النوافذ مع استخدام الجلا المدبوغ في كسوة ظهر السرير وهذا ما يتسم به الروستيك القديم.

\section{نماذج مختلفة لغرف سفرة روستيك}

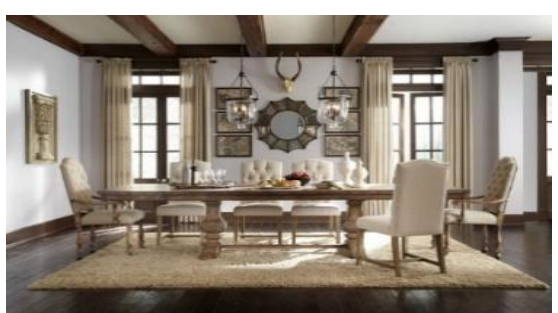

وضوح الطراز الروستيك القديم في الأرجل الخشبية للمنضدة، مع استخدام عروق خشبية في الأسقف والاستعانة ببعض اللوحات الحديثة للامج بينها وبين الروسنيك القديم.

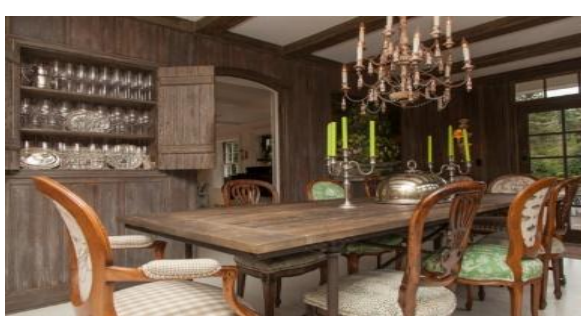

تم تجليد حوائط الغرفة بالأخشاب مع استغلالها كأماكن للتخذين بشكل مبسط و حديث، كما تم دمج طرز أخرى

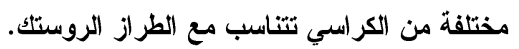




\section{صور من نماذج مختلفة لتصميمات حمامات روستيك}

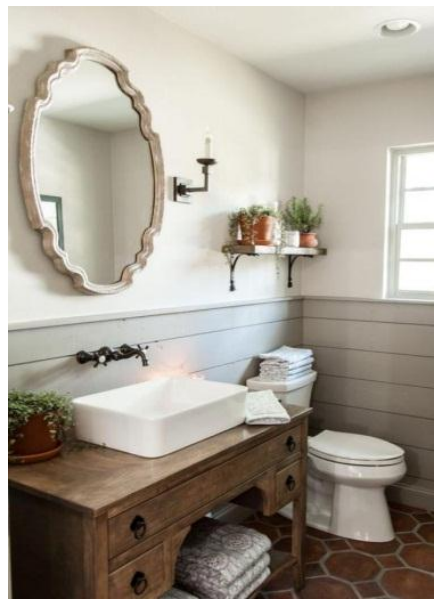

تم معالجة التصميم بطريقة حليثة ويظهر

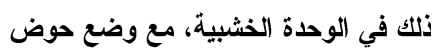

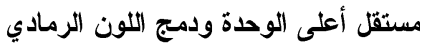
والمر آه الحديثة مع الأخشاب البنية العادية العتيقة.

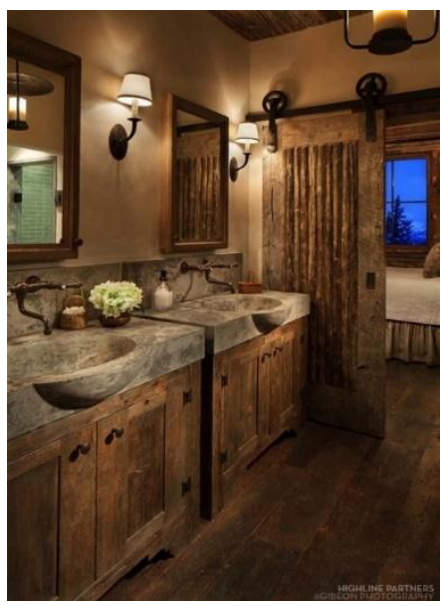

يتميز باستخدام الطراز الروستيك القديم في قطع الأثاث، والأحو اض الرخامية وتغطية الأرضيات بالأخشاب المعالجة ضد الألموان المياه لإعطاء شعور بالقلم و البساطة.

\section{صور نماذج مختلفة لغرف معيشة روستيك}

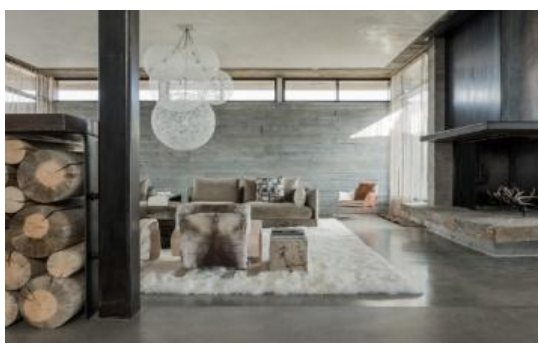

بتميز هذا التصميم بمر اعاة التناست في الامج بين الأماط المختلفة لطرز الأثاث الروستيك والعديث.

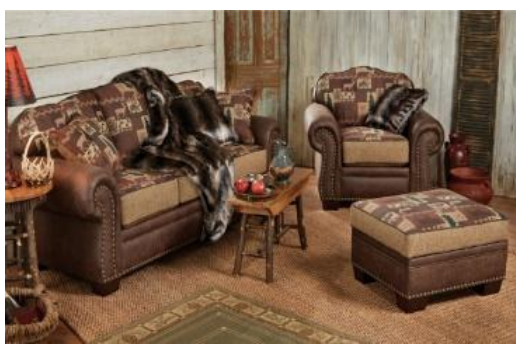

غرفة من الطراز الروستيك القديم ذو الأحجام الضخمة وتتميز باستخدام خامات مختلفة ككسوة الار ائك بالجلد المدبوغ و و القماش. 
ظهر الطراز الكلاسيكي الفرنسي منأثراً بالأحداث الثتاريخية و السياسية في تصميح الديكور الداخلي في القرن الثامن عشر الميلادي في فرنسا، حيث كانت من أكثر الدول تقدماً ورقياً.

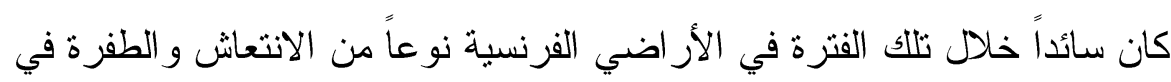

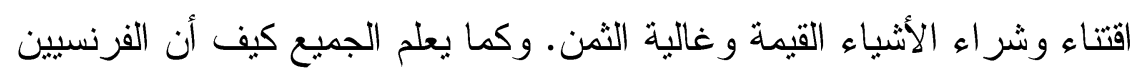

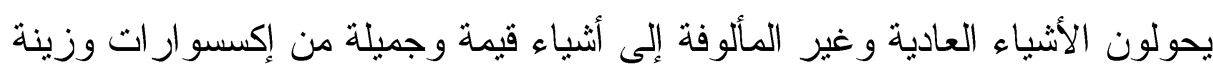
تضاف إلى التصميم العام للايكور بشكل مبهر.

فالطر از الفرنسي هو رفاهية الملوك و عر اقة الفنون، فعندما تصبح الرفاهية سمة

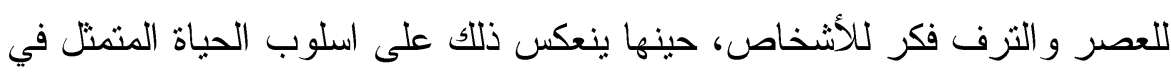

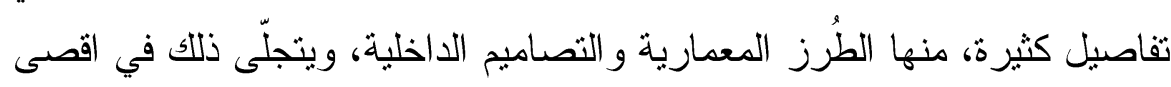
صوره في الطر از الفرنسي.

فالطر از الفرنسي الكلاسيكي في الديكور الداخلي يتم تداوله حتى الوقت الحاضر ، ولم

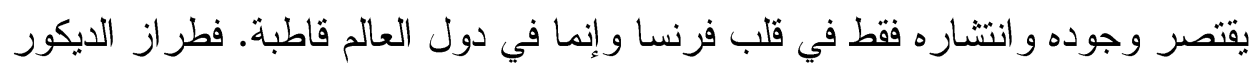

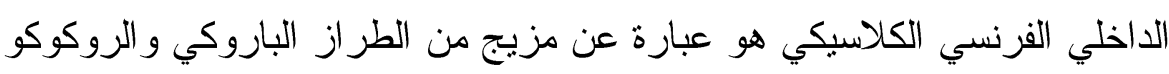

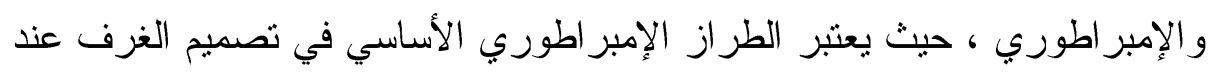

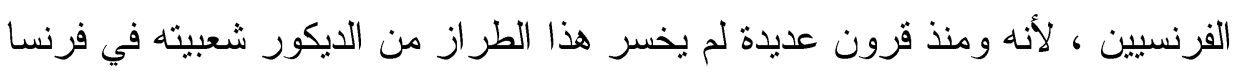

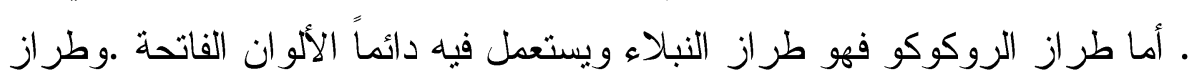
الباروك بساعد في خلق صورة ملكية في الديكور وبقليل من الثتو اضع في المالامح

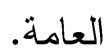

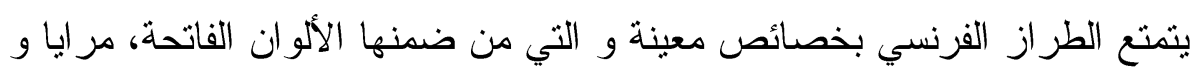

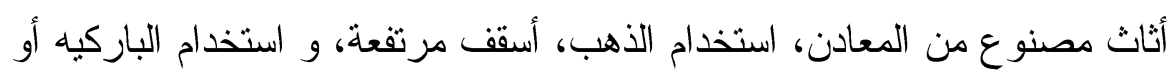




$$
\text { البلاط المصقول على الأرضيات. }
$$

وتتميز التصميمات الداخلية في هذا الطراز (الفرنسي) ، على الأغلب باستعمال ألوان

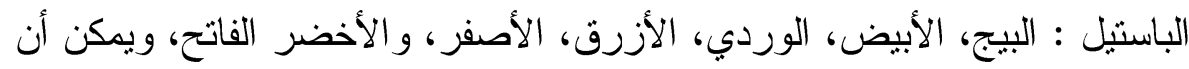
تظهر الظلال الداكنة في تشطيب المفروشات منل : البني، البرونز، و الرمادي. ويتسم هذا الطر از من الديكور بالبساطة و الرومانسية مع طاقة إيجابية . الايكور الفرنسي الداخلي :

الجدران: هناك نو عان أساسيان من أنماط الجدران يمكن تقبلهما في هذا النوع من

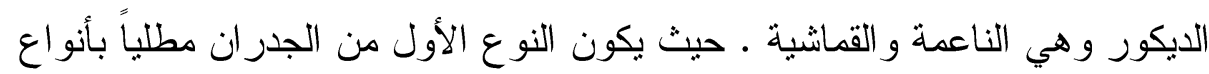

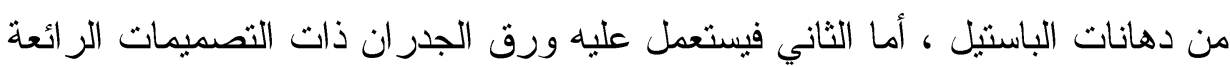

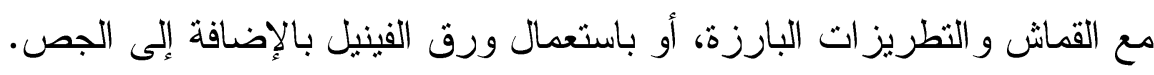
الأرضيات: دائماً ما كانت تغطى الطبقة السطحية من الطابق الأرضي بالباركيه الخشبي ذو اللون الكهرماني المصفر، بالإضافة إلى ذلك يمكن استخدام نوع من البلاط المصقول مع خطوط ذهبية غير تقليدية.

الأسقف: ينبغي تغطية سطح السقف بألو اح من الجبس،ويضاف إليها في المر احل النهائية قو الباً مصنو عة من مادة البوليوريثان.
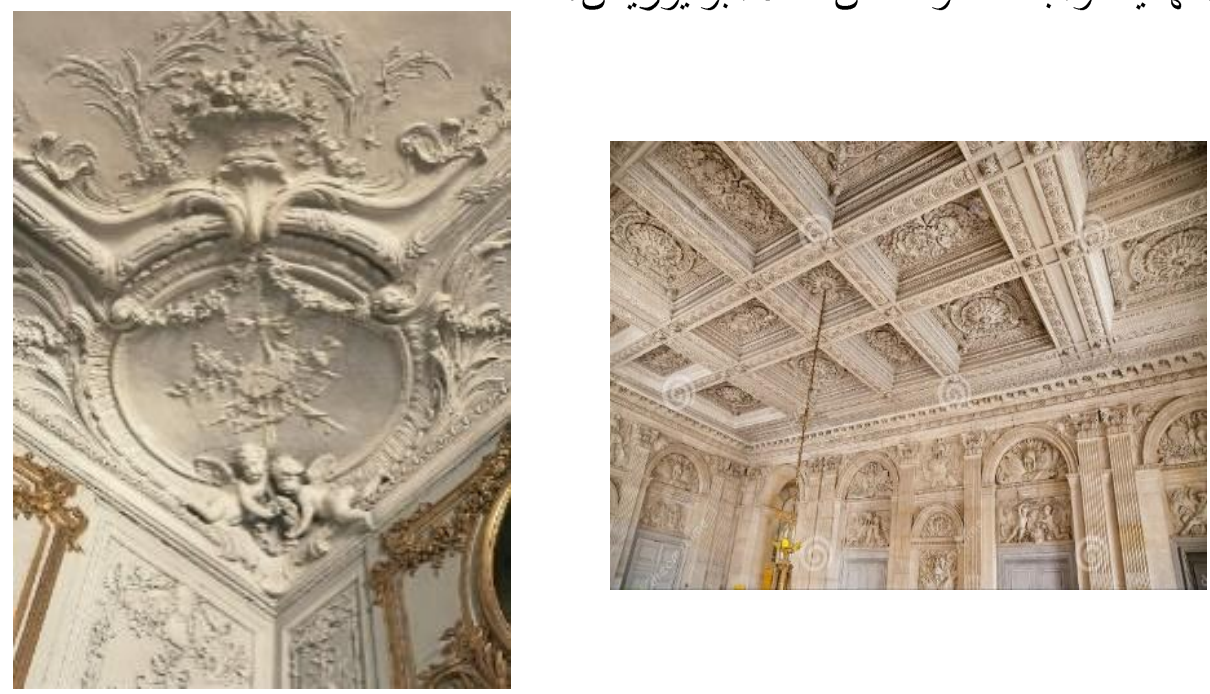
الأثاث: دائماً ما كان يستخدم الأثاث الناعم البسط الذي يتم تتجيده بكسوة أنبقة، مع

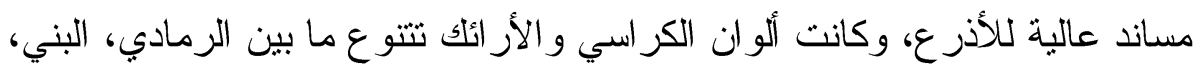

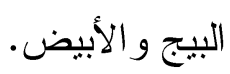

و لايمكن أن نتجاهل الاكسسوار ات التي تم استخدامها في تجميل مسطحات الحيز ات

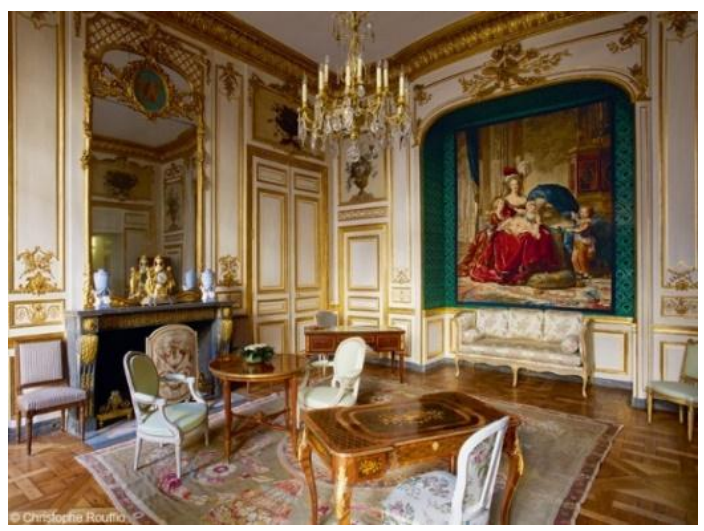

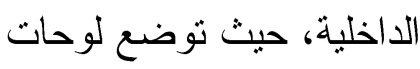

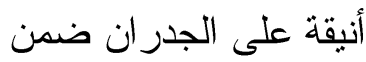
إطار ات فخمة، بالإضافة إلى لى إنى المر ايا. كما يمكن استخدام

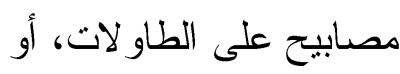

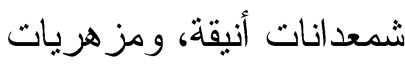

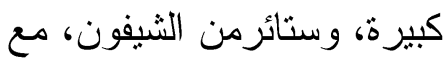

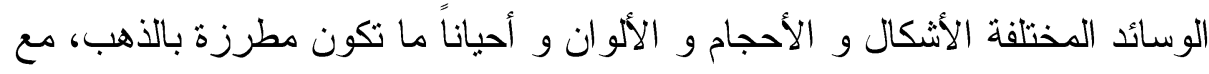
مر اعاة التناغم و التتاسق و التجانس اللوني بين العناصر المختلفة.

ينقسم الطراز الفرنسي إلى عدة فترات وهي : - لويس الر ابع عشر - لويس الخامس عشر - لويس السادس عشر - الامبر اطوري

\section{لويس الرابع عشر (ملك الثمس) XIV}

من اعظم ملوك فرنساءأهتم بالفنون بشكل كبير وكانت فرنسا في عهده أغنى البلاد

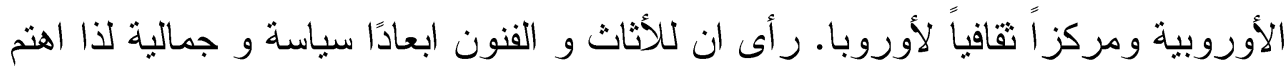
بها وأسرف في تجميل قصوره حتى غدت أبهى القصور الملكية في أوروبا، حيث استعان بالفنانين النابغين لزخرفة وتأثيث قصور فرساي وبالتالي تسلمت فرنسا زمام الفن خلال

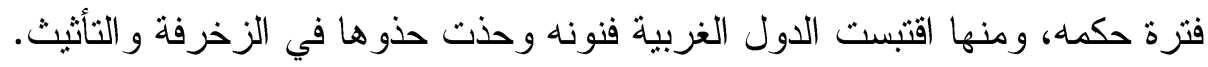

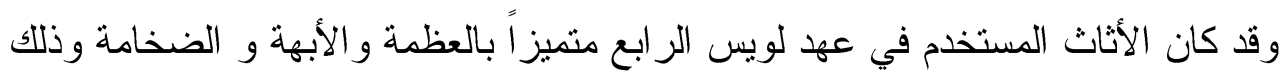
تمجيدا للملك، وتغلب على خطوطه الاستقامة، حيث كانت تستخدم الخطوط المنحنية في حدود ضيقة جداً. 
و هذا الطر از من الأثاث كان ذا صبغة ملكية بحتة، أما طبقة الفلاحين و العمال فلم يكن لهم

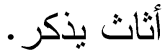

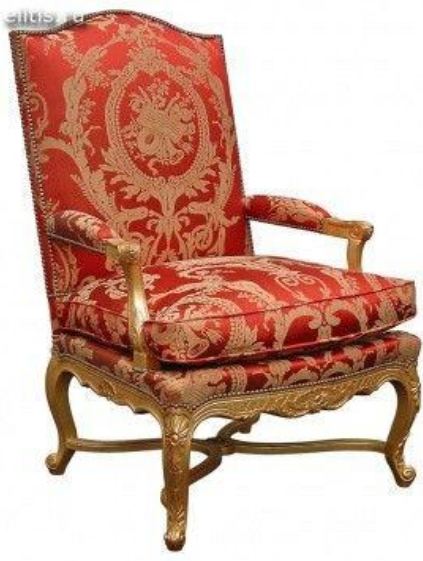

ومن مواصفات هذا العصر : king size المقاسات الملكيّة - خطوط الاثاث مستقيمة - وجود دعامات أسفل الكر اسي بشكل X

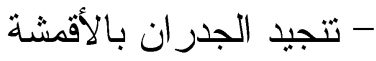
- ثقيل و ذو حفر كثيف - مطعّم بالعاج و النحاس و ولفر الفضة - ظهور فنون الارضيات (صنعت بطريقة هندسية تسمى الباركيه من الحجارة و الخشب ونس

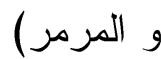

و لأنه بهذا البذخ و التكلف فهو نادر أ ما يستعمل في عصرنا الحالي و يقتصر استعماله على القصور الرئاسية و العرض في المتاحف.

المقاعد: كان تصميم المقاعد يركز على راحة الجالس، فابتكرت الكر اسي ذوات الجناحين (البرجير) و تأكيداً لر احة الجالس كان يتم تتجيد على جيد الجيع أجز ائها الداخلية

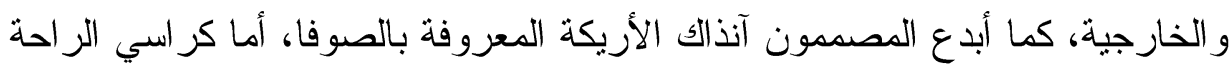

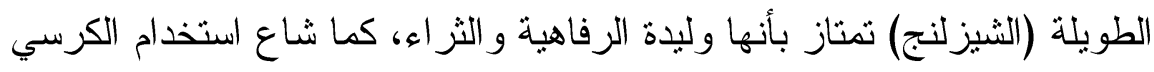
العادي و الكرسي ذو الذر اعين (الفوتيه) و الكرسي المزدوج و المقعد المطوي و المقاعد وليد الخالية من الظهر مثل التابوريه ويسمى بوف، ومثل البانكيت وتشبه الكنبة العادية. 


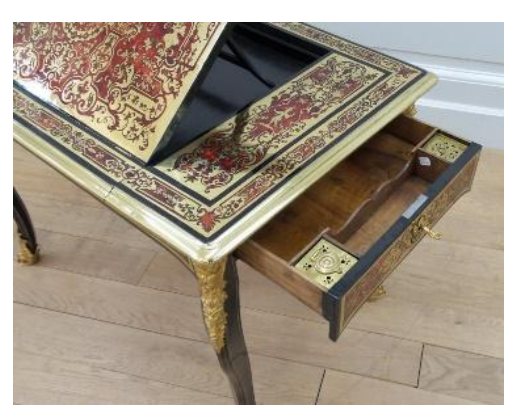

المناضد: تعددث أنو اع المناضد و الطاو لات فمنها الخاصة بالوسط، ومنها منضدة الثاي و القهوة، ومنها ما يعرف بطقطوقة السجائر ، وكان هناك

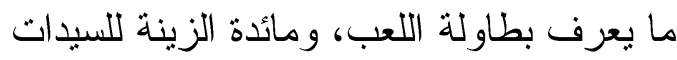

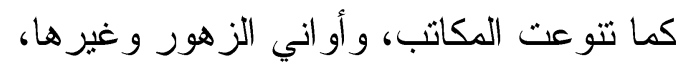

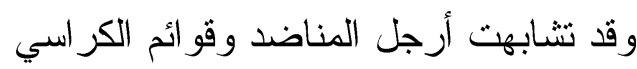

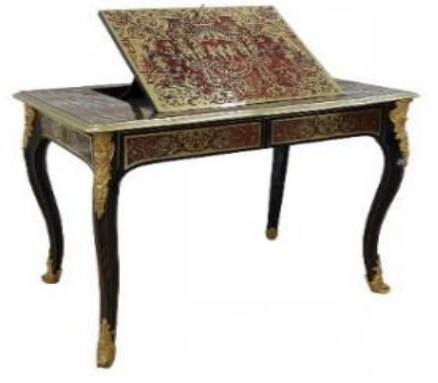

سو اء مربعة القطاع أو المخروطية أو المنحنية،

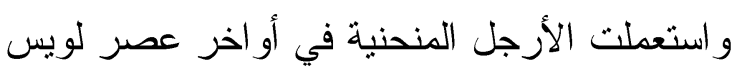

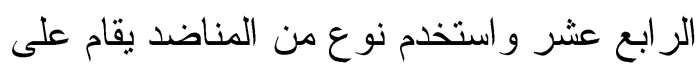

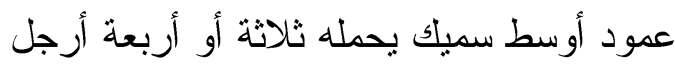

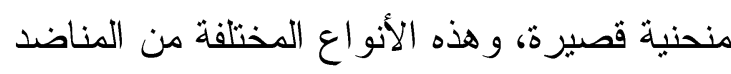
لا نز ال شائعة الاستعمال في مختلف أنحاء العالم سو اء ما كان منها على النمط الحديث أو القديم.

الخزائن والدواليب: فقد شاع استعمال الثيفونيرة و الكمودينو.

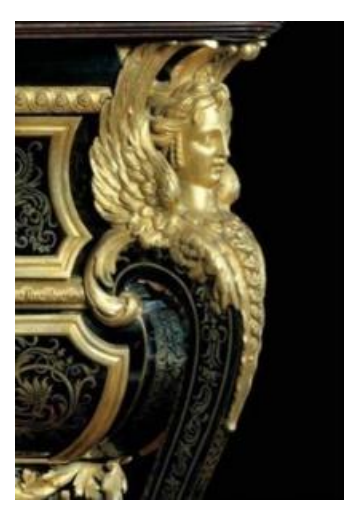

الوحدات الجمالية والزخرفية: وقد اشتملت على الطيور

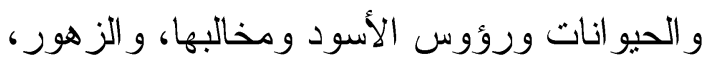

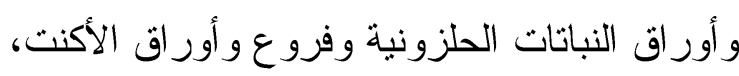

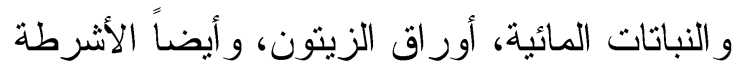

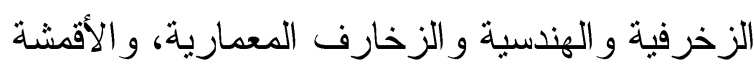
المسدولة و الوحدات المتساقطة. 
أما الأخشاب المستعملة فهي أخشاب الجوز و الأبنوس و اللوز واستخدم في التطعيم العاج و عظام الحيو انات و الأصداف البحرية وقو اقع السلاحف و الفضة و النحاس.
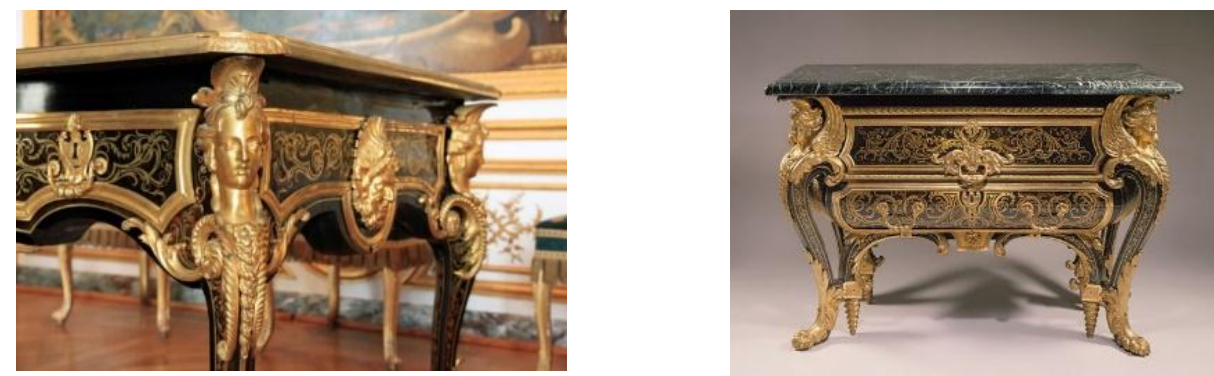

\section{لويس الخامس عشر XV}

كان لويس الخامس عشر مائلاً للأدب و الفنون ، و رغم انه حاول ارتداء قناع الملك الجبار الا ان طيبته و رومانسيته و عاطفته طغت عليه لذا تحول الطر از الملكي الضخر ماند

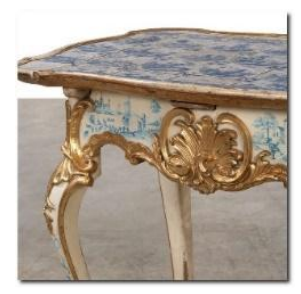

الى خطوط ناعمة منحنية لتناسب النساء اكثر .

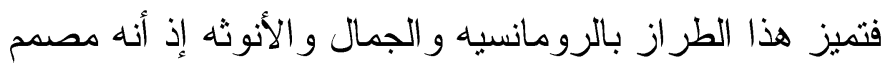

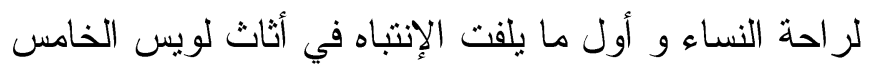
عشر هي الانحنائات في خطوط تصميم الأثاث و الجدران

و الأبو اب و الاسقف و زو الإيا الغرف المعمارية بعد أن كانت خطوط مستقيمه في عهد لويس

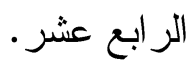
كما تميز بالزخرفة و النحت بأشكال المحار حتى سمي هذا العصر بال"روكوكو" وهي كلمة تعني الصدفة أو المحارة غير المنتظمة الشكل ذات الخطوط المنحنية و التي استمدت منها زخارف نلك الفترة.

يعد هذا الطر از امتدادا لطر از الباروك ولكن بمقاييس جمالية تتسم بالسلاسة و الرقة،

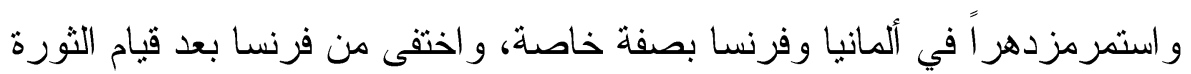

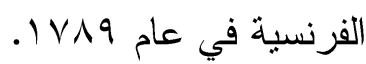
وتميز هذا الطر از بظهور قطع الاثاث الانثوية مثل ( طاولات التزيين ، طاو لات المطالعة

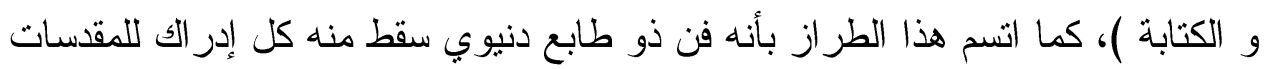


و التحليق فيما ور اء الطبيعة بما فيها الأساطير القديمة، واتخذ شكلا دنيوياً مسرحيًا.

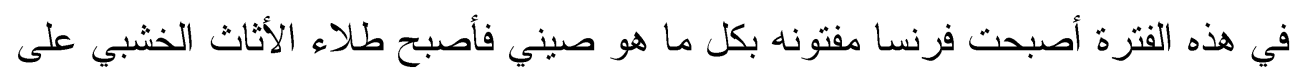

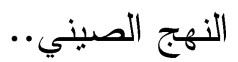

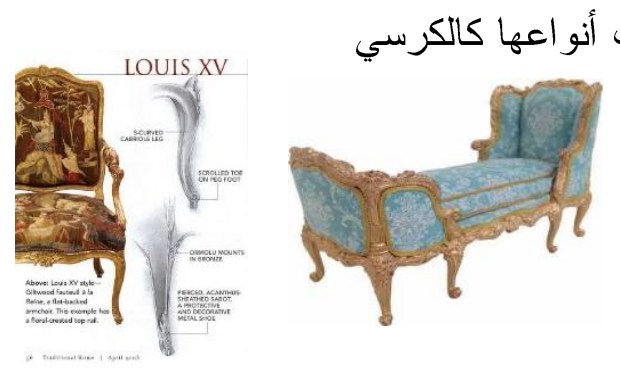

$$
\begin{aligned}
& \text { العادي و الكرسي ذي المتكأين، وكرسي }
\end{aligned}
$$

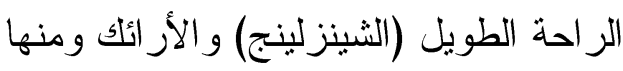

$$
\begin{aligned}
& \text { الصوفا المقتبسة من فكرة الكنبة } \\
& \text { الإسطمبولي. }
\end{aligned}
$$

المناضد والمكاتب: ورغم تعدد أثكالها إلا أنها لم تشذ عن القاعدة الأساسية التي سارت

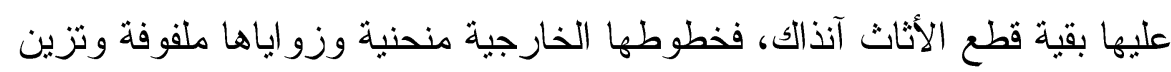
بالماركيتزي و السبائك البرونزية المذهبة و الحشوات المصنو عة من الصيني الفاخر و المعروف بالسيفر . بالمبن

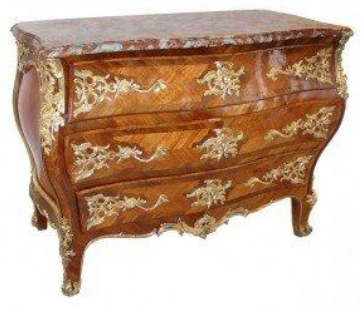

الخزائن والدواليب: كانت خز انة الأدر اج من أهم الخز ائن التي

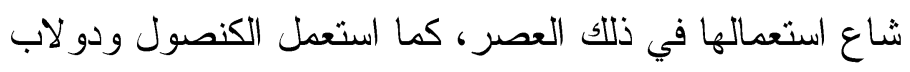
الز اوية. الوحدات الجمالية والزخرفية: استخدم المصممون فتر الأخشاب الثمينة، و التطعيم الماركتري وكذلك التطعيم بسبائك

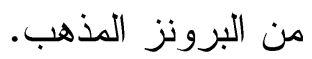


وكان الأثاث يدهن بطبقة من اللاكية الصيني و الياباني، ومن بين الوحدات الثي تزين

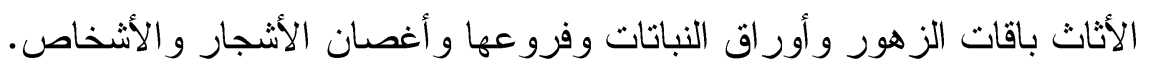
ومن أهم الأخشاب المستخدمة الورد والجو وقد كان الماهوجني من الخشب السائد في

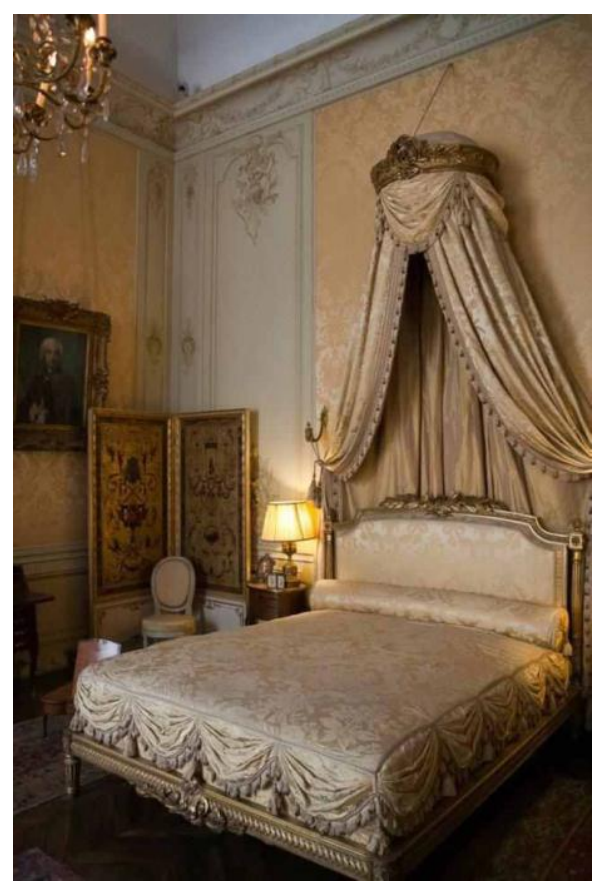

$$
\text { صنع الأثاث و قتنئ. }
$$
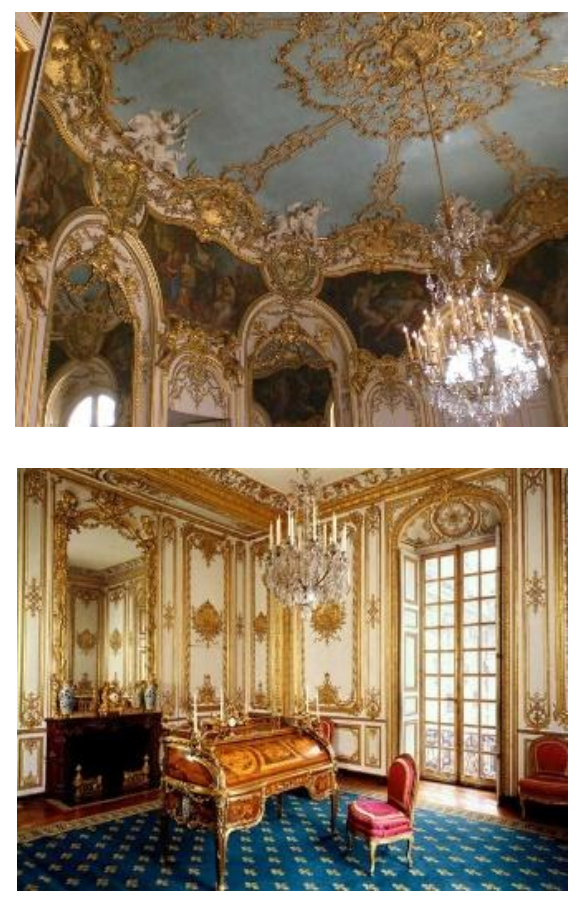

\section{XVI لويس السادس عشر}

كان لويس السادس عشر و الملكة ماري أنطو انيت على جانب كبير من الذوق الفني

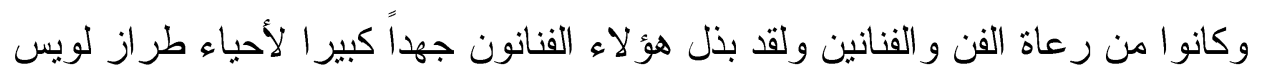
السادس عشر، فعادت الخطوط المستقيمة للظهور و تبعاً لهذا ظهرت الأعمدة الرومانية

$$
\begin{aligned}
& \text { في قطع الاثاث. اصبح للكر اسي اشكال جديدة } \\
& \text { ( المربع، البيضاوي ، الالة موسيقية ) }
\end{aligned}
$$


المقاعد: في الوقت الذي كانت أرجل الكراسي في عصر لويس الخامس عشر منحنية، نجدها مسنقيمة دون استثاء في طر از لويس السادس عشر ولكن الكن بعدة أثنكال: منها الرجل المربعة القطاع، و المخروطة. و كانت غالباً ما تصنع من الخشب الز ان، وتدهن باللون الرمادي المشعر بالابيض.
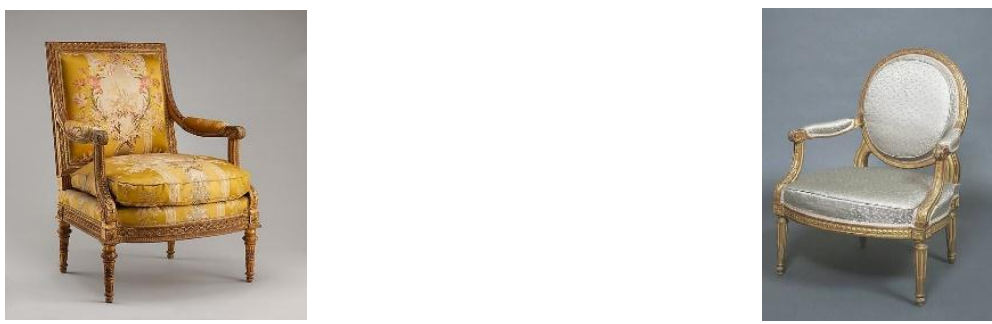

الخزائن والدواليب: كان الكمود من أهم قطع الأثاث التي شاعت في عصر لويس السادس

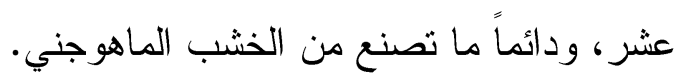
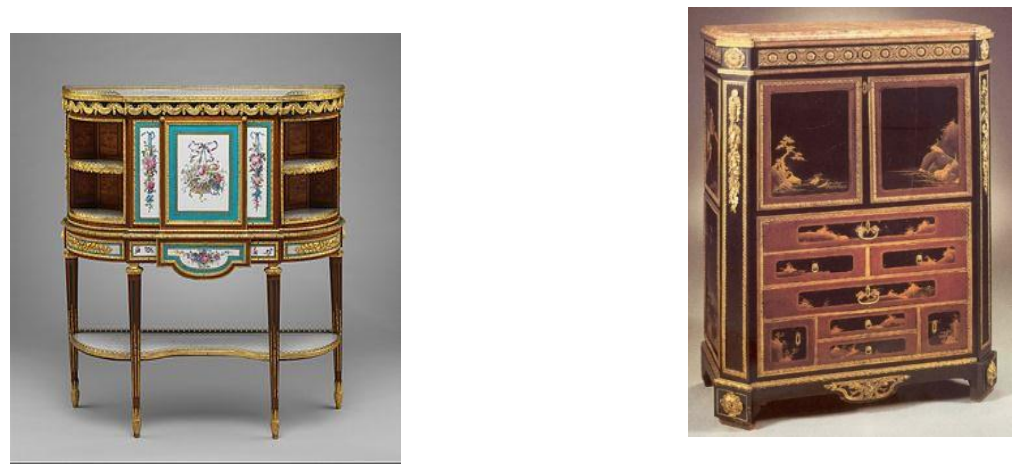

الوحدات الجمالية والزخرفية: استمر في هذا العصر استخدام العناصر الزخرفية

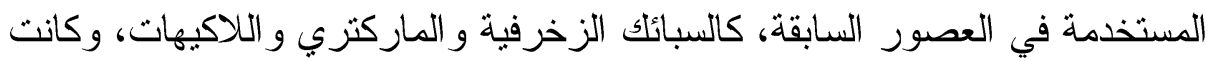

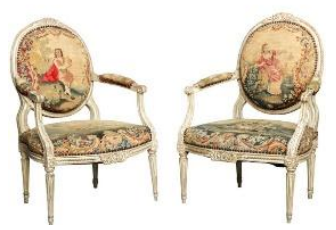

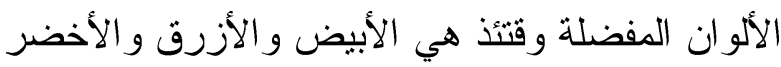

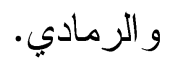

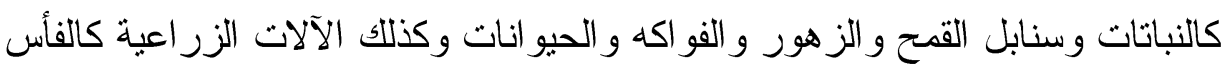

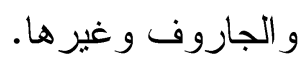


وبالنسبة للأخشاب المستعملة فقد كان الماهوجني هو السائد في ذالك الطر از، و استخدم فيها أشغال التطعيم و الماركثري، وأخشاب الأبنوس و الورد و الجميز و الجوز ، و استعمل كذلك العاج.

صور توضح استخدام دهانات اللاكيه لطلاء قطع الأثاث المختلفة
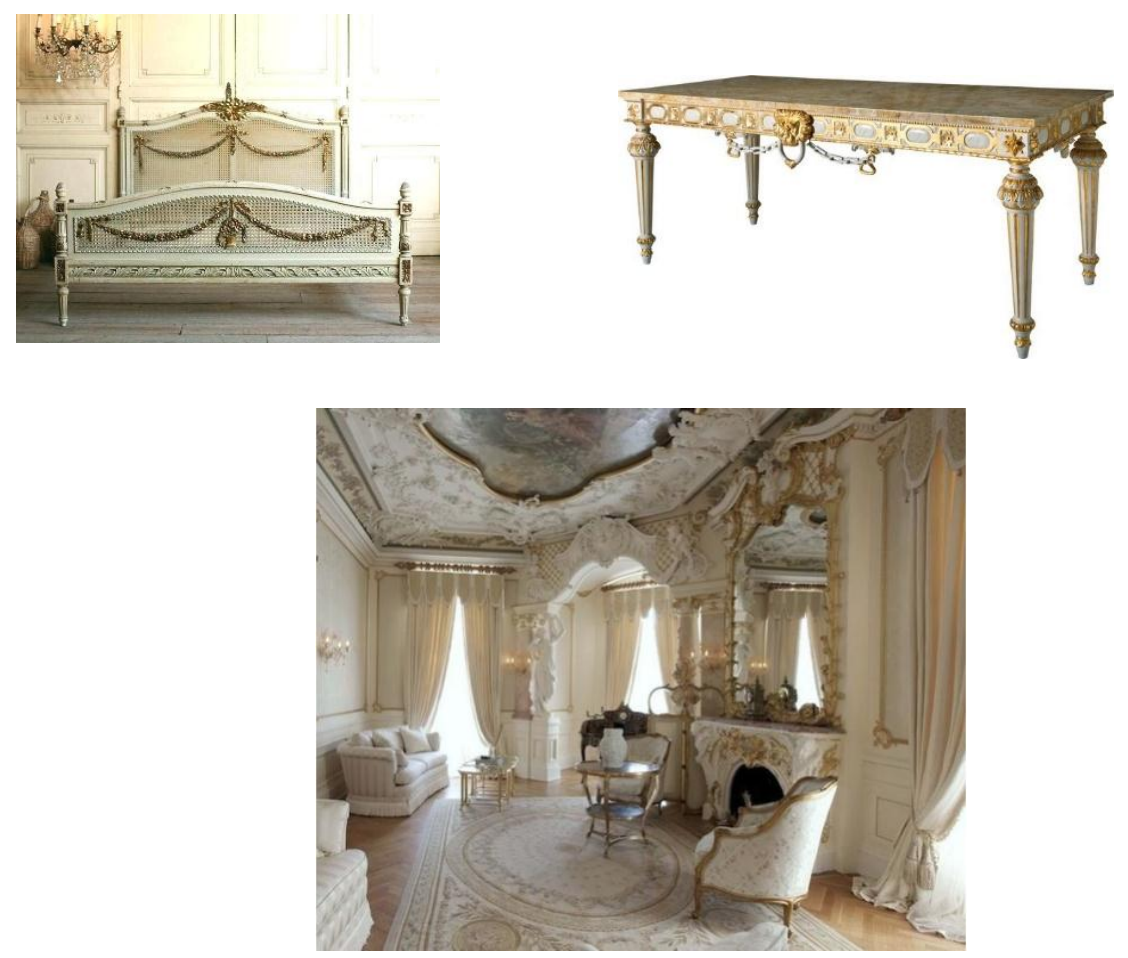


\section{الطراز الامبراطوري (نسبة الى الامبراطور نابليون بونابرت)}

ظهر في فرنسا في عهز نابليون مع بداية القرن الثاسع عشر، وهو طر از دخيل غير

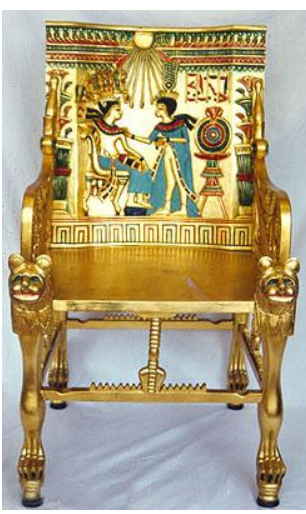

عرش الملك توت عنخ امون (الدولة المصرية القديمة)

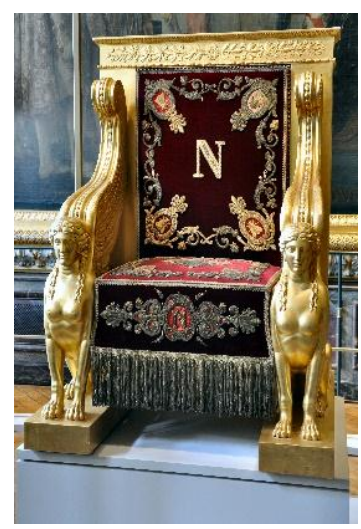

عرش الامبراطور نابليون

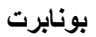

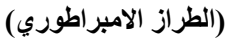

فرنسي المظهر، و إنما هو محاولة لترجمة الفنون الكلاسيكية و الأشورية و المصرية القديمة تزجمة فرنسية. و قد سبقته مرحلة إنتقالية بعد فيام الثورة الفرنسية عام VA9 تثرك اي أثز يذكر على الفنون لكثرة الإضطر ابات في هذة الفترة التي سميت بعهد الديكتاتور سوى

إضافة الحراب و أكاليل النصر و الأبدي المنشابكة على زخارف الطر از السابق. فقد ثار الثوار على صناع الاثاث، وكانت فترة إنتقاليه برزت بها بعض الزخارف الرومانيه و الإغريقيه و الزخارف التي كانت ثزمز للتورة.

و تميز الطر از الامبر اطوري بظهور الأعمدة و التماثيل و الزخارف المنقولة من الحضار ات القديمة في قطع الأثاث و الإحتفاظ بالتماثيل و استمر ار الاسلوب الكلاسيكي الأي يتميز بالقوة و المتانة و الجمال و الر احة وكثرة التشكيلات الزخرفية و الإنحناءات.
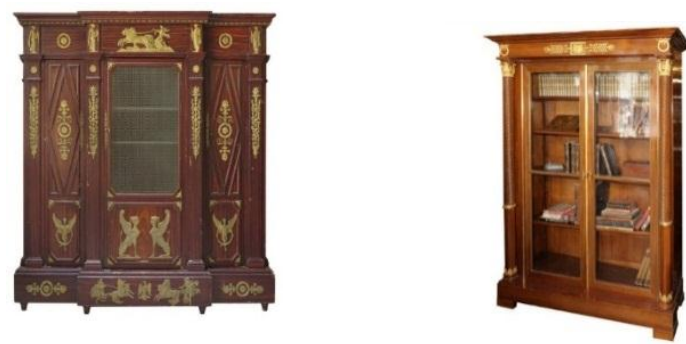

في عام ؟ • أم أصبح نابليون الحاكم الوحيد بعد أن كان أحد الأشخاص المسؤولين عن السلطه بعد الثورة على الملك لويس السادس عشر، وفي هذه الفترة أصبح الأثاث بعكس الإمبر اطوريه و عظمتها ورغم أن نابليون ثم نفيه في عام 0 ام ام إلا أن صناع الأثاث 
ظلو ا يصممون هذا الطر از فترة من الزمن حتى ظهور الثورة الصناعيه في العام • بـ أم.ـ

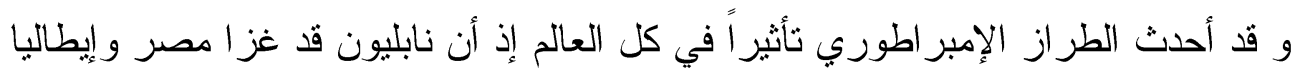

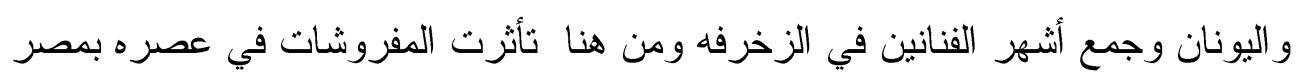
و إيطاليا و اليونان. و وجنان.

ومن مميزات الطراز الامبر اطوري:

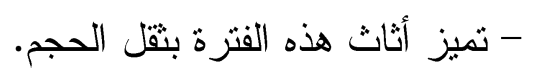
- إستخدام الخشب الطبيعي و المطلي و المعادن لزخرفة الأثاث مع تبسيط الأسطح. IIIIIII - الإحتفاظ بالتمانل واستمر ار الاسلوب الكلاسيكي واني بصورة كبيرة. - كثرة استخدام التماثيل الرومانية و الاسُود و الطيور

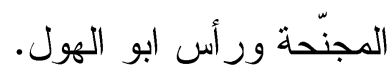

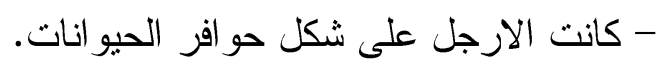
- تأثز بالطر از الإغريقي و أخذ منه السرير بشكل

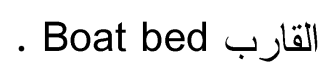
- كانت الزخارف منأثرة بالعصر الفرعوني و الإغريقي و الروماني.

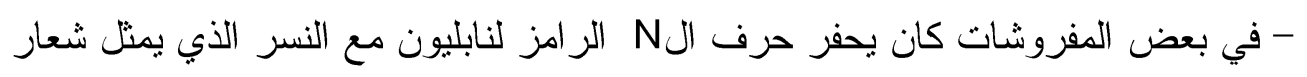
فرنسا في ذلك الوقت. الكر اسب : كانت ذات مساند خشبية خلفية ومقاعد منجده، وفي بعضها كانت قو ائم المخادع عبارة عن تماثيل رومانيه أو أسود مجنحه أو جسم أسد مجنح مع ر أس لتمثال آدمي أو أو أوفي طيور •
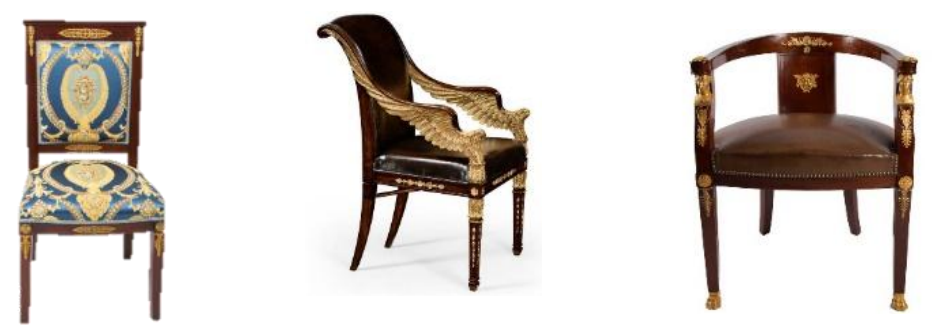


$$
\text { الأسرة : تصميمات الأسرة و الار ائك كانت مأخوذه من الطر از الإغريقي. }
$$

بالر غم من أن تاريخ تصميمات هذه الطرز من الأثاث يعود الى القرون الماضية، إلا انه
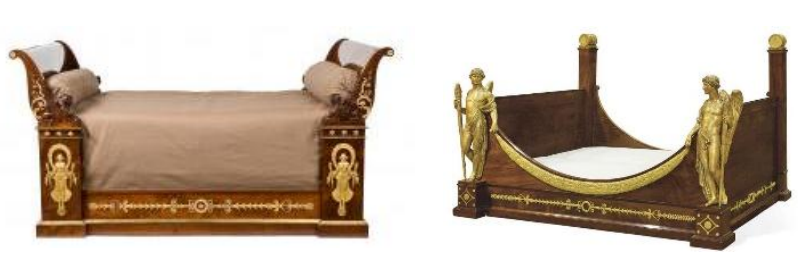

حتى الآن ماز الت تستخدم عناصر ها في تنفيذ قطع مالع الأثاث المختلفة في حياتتا المعاصرة، في محاولة من

المصممين لامج الماضي بالحاضر من خلال استمر ار صور هذه التصميمات حتى يومنا هذا. 


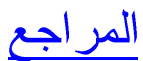

1. Aronson, Joseph. 1956, The encyclopedia of furniture, 3rd ed., Crown Publishers.

2.

Foley, Edwin. The Book of Decorative Furniture, Vol. 1, London: T.C. and E.C. Jack, 1910.

3. Almuhands.org, 16 Dec. 2006, " طر از الأثاث "الفرنسي $\underline{65795 .}$

4. "موقع بكر ا ".أصالة طر از الروستيك في الديكور ات المنزلية July 30 July 2015, www.bokra.net/Article-1306841.

5. “ستار تايمز ".الأثاث الفرنسيى, 7 Jan. 2007, www.startimes.com/?t=3213113.

6. Consultancy, ALGEDRA Interior Design. " الطر از الفرنسي في رالداليكور الداخلي algedra.ae/ar/blog/french-style-in-the-interior-a-classicof-style.

7. "روكوكو." Wikipedia, Wikimedia Foundation, 7 Apr. 2018.

8. http://www.interiordezine.com/wpcontent/uploads/2013/09/Part-5-Syles-Periods-and-DesignHistory.pdf 